\title{
ПОЛИТИЧЕСКИЙ КРИЗИС В СЛОВАКИИ 2018 г.: ОТСТАВКА Р. ФИЦО И НОВЫЙ КАБИНЕТ П. ПЕЛЛЕГРИНИ
}

Аннотация. В статье показан ход развития политического кризиса в Словакии в феврале-марте 2018 г., в результате которого премьер-министр Р. Фицо был вынужден уйти в отставку и впоследствии был назначен новый кабинет министров под руководством П. Пеллегрини. Автор акцентирует внимание на возможных последствиях для политической системы Словакии произошедших перемен.

Ключевые слова: Словакия, политический кризис, досрочные выборы, Я. Куцяк, Р. Фицо, П. Пеллегрини, Ндрангета.

Конец февраля 2018 г. был ознаменован началом глубокого политического кризиса в Словакии, поводом для которого послужило убийство журналиста интернет-портала Aktuality.sk Яна Куцяка и его подруги Мартины Кушнировой. С самого начала следствие выдвинуло предположение о том, что главным мотивом преступления стала профессиональная деятельность молодого человека, который занимался расследованием связи итальянской преступной организации Ндрангеты с предпринимателем итальянского происхождения Антонино Вадала, проживающего на территории Словакии, и его возможных контактах с представителями правящей партии Смер-Социал-Демократия. Последняя статья журналиста, опубликованная уже после его смерти, была названа «Итальянская мафия в Словакии. Её щупальца простираются в политику» 1 .

Важно отметить, что подобное происшествие - насильственная смерть репортёра стала экстраординарным событием, первым в истории современной Словакии случаем подобного рода. В этой связи не удивительно, что реакция словацкого общества была незамедлительной и осуждающей произошедшее. Так, премьер-министр Словакии Роберт Фицо это преступление охарактеризовал как «беспрецедентное нападение на свободу печати и демократию», президент страны Андрей Киска пообещал, что виновные в этом хладнокровном убийстве понесут заслуженное наказание. Инцидент получил международное звучание - его осудили премьер-министр Чехии А. Бабиш, её президент М. Земан; председатель Еврокомиссии Ж.-К. Юнкер во время посещения Белграда высказался, что «убийства или преследования журналистов не допустимы ни для европейского, ни для какого-либо другого демократического государства».

Трагическое событие повлекло за собой формирование массового общественного движения в память о погибших молодых людях. Вечером 26 февраля в Братиславе на площади Словацкого национального восстания произошло памятное собрание жителей столицы. Подобные мероприятия имели место также в Праге на Вацлавской площади и в Брно на площади Коменского. 28 февраля в Братиславе прошло шествие, в котором приняло участие не-

(C) Ведерников Михаил Владимирович - научный сотрудник Центра Вишеградских исследований ИЕ РАН, кандидат исторических наук. Aдpec: РФ, 125009, Москва, ул. Моховая, д. 11, стр. 3. E-mail: vishma@mail.ru.

DOI: http://dx.doi.org/10.15211/vestnikieran2201812

Статья подготовлена при финансовой поддержке РФФИ в рамках проекта № 17-07-00016 «Россия и Центральная Европа: проблемы и перспективы взаимоотношений в условиях мирового политического кризиса».

${ }^{1}$ URL: https://www.aktuality.sk/clanok/568007/talianska-mafia-na-slovensku-jej-chapadla-siahaju-aj-do-politiky/ 
сколько сотен человек. Его организатором выступила оппозиционная партия «Обычные люди и независимые личности». Далее, 2 марта состоялся митинг под названием «Не хотим опять в 90-е», который, по словам организаторов, не носил политического характера. Расширение движения последовало спустя неделю, когда 9 марта в демонстрациях под лозунгом «За достойную Словакию» участвовали 48 словацких и 17 зарубежных городов. В этот раз их протестное, антиправительственное содержание стало очевидным, поскольку участники выступали против Р. Фицо и министра внутренних дел Р. Калиняка, требовали «надёжной и не коррумпированной власти», скорейшего расследования убийства Я. Куцяка. По оценкам наблюдателей общее количество людей, пришедших в этот день на митинги, суммарно составило около 120 тыс. человек; только в Братиславе количество участников приблизительно оценивалось в 50 тыс. человек ${ }^{1}$. Кульминацией общественного движения стала самая крупная общественная акция со времён бархатной революции 1989 г., прошедшая 16 марта в Братиславе, на которой, по данным её организаторов, присутствовало свыше 65 тыс. человек.

Массовая волна недовольства была незамедлительно поддержана оппозиционными политическими силами, которые использовали её как повод для начала широкомасштабной антиправительственной кампании. Программа-максимум протестующих заключалась в проведении досрочных парламентских выборов, программа-минимум - отставка Р. Фицо и Р. Калиняка. Последний, по мнению протестующих, стал символом политических злоупотреблений, которые привели к возможности совершения такого преступления как убийство Я. Куцяка.

Нападки на Фицо и Калиняка со стороны их противников случались и ранее. Так, осенью 2016 г. разразился громкий политический скандал, в ходе которого Калиняка обвинили в связях с предпринимателем Л. Баштернаком, находившемся под следствием в связи с неуплатой налогов. В тот раз политический кризис достиг своего апогея, когда оппозиции удалось назначить на 23 сентября чрезвычайную сессию в парламенте, на которой должен был обсуждаться вопрос о доверии Р. Фицо. Помимо прочего, перед депутатами был поставлен вопрос о смещении со своей должности Р. Калиняка. Однако с самого начала подобная инициатива, ввиду наличия парламентского большинства у правящей коалиции, была обречена на провал. Повторная попытка выразить недоверие премьер-министру состоялась 16 февраля 2017 г. Её итог также был не в пользу оппонентов Фицо. Однако сам факт проведения подобных процедур отражает состояние накала внутриполитических отношений среди словацкого истеблишмента на протяжении всего третьего премьерского срока Р. Фицо.

Помимо давления общественного мнения и оппозиции на кабинет Р. Фицо, члены которого стали рассматриваться виновниками случившегося, стабильность политической ситуации в стране стала подтачиваться появлением разногласий внутри самого коалиционного правительства (Смер-СД, Словацкая национальная партия (СНС), Мост-Хид), в рамках которого представители Мост-Хид заявили о недопустимости нахождения в правительстве Р. Калиняка. Более того, 12 марта на центральном собрании партии было принято неоднозначное заявление, согласно которому не исключалась возможность досрочных выборов после проведения переговоров с партнёрами по коалиции или вообще выходе из неё. Между тем, в документе

1 URL: https://dennikn.sk/1056566/slovensko-zazilo-najvacsie-demonstracie-v-historii-v-bratislave-bolo-podla-odha dov-50-tisic-ludi/

Научно-аналитический вестник ИЕ РАН, 2018, №2 
содержалось предложение о том, что руководство партии имеет право следовать обстоятельствам и принимать решение на их основании ${ }^{1}$. В тот же день, следуя мотиву сохранения коалиции, Р. Калиняк подал в отставку. В ходе пресс-конференции он сказал: «В эти сложные минуты для Словакии важно сохранить стабильность. Моё решение основано на желании успокоить страсти вокруг сложившейся ситуации» ${ }^{2}$.

Ощущая возможность распада коалиционного правительства и досрочных выборов, Р. Фицо 15 марта подал в отставку, что в свою очередь означало и автоматическую отставку действующего кабинета ${ }^{3}$. Между тем, свой уход он обозначил тремя условиями: 1) новый премьер-министр должен быть назначен из партии Смер-СД; 2) результаты парламентских выборов 2016 г. не могут быть подвергнуты сомнению; 3) коалиционное соглашение между Смер-СД, СНС и Мост-Хид сохранится как основа нового кабинета. На момент своего заявления Фицо уже знал о согласии всех участников теперь уже бывшего правительства принять участие в составлении его обновлённого варианта. Президент А. Киска принял отставку Фицо, но в соответствии с установленными правилами продлил её полномочия до момента назначения нового правительства. Будучи активным противником Фицо и его партии, президент не утвердил сразу же предложенную Фицо кандидатуру на пост будущего премьер-министра - Петера Пеллегрини, поскольку в это же самое время в Национальном совете Словакии обсуждался предложенный оппозиционными партиями законопроект о проведении досрочных выборов. В дальнейшем он не получил необходимого конституционного большинства (90 голосов из 150). В таких обстоятельствах А. Киска был вынужден наделить П. Пеллегрини, который предоставил подписи 79 депутатов парламента об их согласии с его назначением, полномочиями на составление нового кабинета министров ${ }^{4}$.

Утвердить предложенный вариант правительства с первого раза не удалось. Возникли противоречия по поводу кандидатуры на пост министра внутренних дел. Вторая попытка последовала 22 марта. В этот день, спустя практически ровно два года с момента вступления в должность третьего правительства Р. Фицо (23 марта 2016 г.), А. Киска после разговора с предложенными на рассмотрение кандидатами одобрил состав нового кабинета министров ${ }^{5}$. Говоря о нём, необходимо отметить, что основные изменения коснулись представителей партии Смер - основного объекта недовольства со стороны участников мартовских манифестаций. Так, партия была вынуждена сменить трёх министров. Место Пеллегрини на посту министра по вопросам инвестиций и информатизации занял Рихард Раши. Министром культуры вместо Марека Мадьярича, который в начале марта подал в отставку, стала Л. Лашакова. В свою очередь новым министром внутренних дел на смену Р. Калиняку был назначен беспартийный Томаш Дрюкер, личность которого, по словам Пеллегрини, не возбуждала в противостоящих лагерях заметных противоречий и который смог стать антикризисным менеджером в сложившейся напряжённой ситуации. Остальные члены бывшего правительства Р. Фицо

${ }^{1}$ URL: https://www.aktuality.sk/clanok/572024/most-hid-chce-predcasne-volby-inak-vystupi-z-koalicie/

${ }^{2}$ URL: https://slovensko.hnonline.sk/1709259-minister-vnutra-robert-kalinak-rezignoval/

${ }_{4}^{3}$ URL: http://www.teraz.sk/slovensko/fico-podal-demisiu-na-post-predsedu-vla/314016-clanok.html/

4 URL: https://domov.sme.sk/c/20786573/prezident-vymenuje-pellegriniho-vladu-kabinet-ma-schvalit-svoj-program. html/

${ }^{5}$ URL: https://www.prezident.sk/article/prezident-kiska-vymenuje-novu-vladu-spokojny-vsak-nie-je/

Научно-аналитический вестник ИЕ РАН, 2018, №2 
остались на своих местах: министр финансов - Петер Кажимир, министр труда, социальных дел и семьи - Ян Рихтер, министр экономики - Петер Жига, министр иностранных дел - Мирослав Лайчак, министр здравоохранения - Андреа Калавска.

Словацкая национальная партия продолжила работу в прежнем составе, а именно: министр обороны - Петер Гайдош, министр сельского хозяйства - Габриела Матечна, министр образования - Мартина Любиова. Партия Мост-Хид частично обновила свой состав. Так, министр юстиции Люция Житнянска, принявшая решение не участвовать в новом кабинете Пеллегрини, была заменена на Габора Гала. Другие представители партии министр транспорта Арпад Эршек и министр окружающей среды Ласло Шоймош остались выполнять полномочия, возложенные на них в предыдущем правительстве.

Оценивая вступление в должность нового премьер-министра, эксперты практически единогласно говорят о том, что Р. Фицо продолжит оказывать существенное влияние на расстановку политических сил в стране, не давая Пеллегрини возможности принимать самостоятельные решения. В день своей отставки он дал ясный сигнал о том, что он не имеет намерений уходить из политики и будет якобы прикрывать своему преемнику тыл, что, по мнению журналистов издания Sme, приведёт к тому, что он станет повсюду «тенью», которая будет довлеть над действующим премьером и воздействовать на осуществление задуманных им шагов ${ }^{1}$.

Одновре́менно с этим Р. Фицо остаётся главой наиболее влиятельной политической партии Словакии Смер-СД, что также сохраняет за ним действенные рычаги влияния на принимаемые решения. Между тем, среди политологов существуют сомнения по поводу жизнеспособности подобного дуализма, когда главная должность в политическом руководстве страной и партией будут находится в руках разных людей. Политолог Э. Лаштич считает, что в Словакии не было удачного опыта подобного раздвоения полномочий. Показательным примером служит ситуация, сложившаяся в 2011 г. вокруг кабинета премьер-министра Иветы Радичовой, не занимавшей пост главы партии, и поэтому не пользовавшейся достаточным доверием среди своих соратников, что в итоге привело к преждевременной отставке её правительства, которое не получило необходимого количества голосов в парламенте в свою поддержку в вопросе о вхождении страны в систему Европейского стабилизационного механизма ${ }^{2}$.

Для комментаторов также свойственно сравнение нового политического расклада в Словакии с ситуацией в Польше, где лидер партии Право и Справедливость Ярослав Качиньский не является главой кабинета, но при этом играет важную роль в политической жизни государства, которая выражается, по их словам, в том, что он «из-за кулис дергает за нитки своих марионеток» и приводит в жизнь нужные ему политические решения. Таким образом, журналисты считают, что в слабом премьере П. Пеллегрини Фицо нашёл своего Матеуша Моравецкого (стал председателем Совета министров Польши в декабре 2017 г.) Подобные алармистские настроения, в которых наружу проступает боязнь наступления «польского сценария», свойственны значительной части словацких либеральных экспертов.

${ }^{1}$ URL: http://www.ceskatelevize.cz/ct24/svet/2421130-fico-jako-dalsi-kaczynski-svemu-nastupci-bude-dychat-na-krkpisi-slovaci/

2URL: https://spravy.pravda.sk/volby/clanok/243573-vlada-ivety-radicovej-stratila-doveru-poslanci-neschvalili-euroval/ Научно-аналитический вестник ИЕ РАН, 2018, №2 
Между тем, в словацком дискурсе присутствует мнение о том, что действия Фицо были оправданы, поскольку они были направлены на продолжение политики его кабинета и сохранение его достижений.

При всей неожиданности развернувшихся событий в конце февраля - начале марта 2018 г., которые привели к отставке кабинета Фицо в середине положенного срока, можно говорить о том, что исход кризиса для нынешней политической системы Словакии, с доминирующим положением партии Смер-СД, был благополучным. Прежде всего, это выразилось в том, что удалось избежать проведения досрочных выборов, которые изменили бы расстановку сил в словацком парламенте. Скорее всего, внеочередное голосование на волне народного недовольства привело бы к падению популярности Смер-СД и к дальнейшим перестановкам в правительстве не в пользу этой партии. Так, недавние результаты опроса общественного мнения показали, что уровень поддержки партии снизился на $1 / 5$ и теперь составляет около $20 \%$. Несмотря на отставку Р. Фицо, он останется ключевым игроком в политической жизни Словакии, который будет и дальше оказывать определяющее влияние на принятие решение внутри государства.

Говоря же о том, почему политический кризис в Словакии ограничился отставкой действующего кабинета министров и не был завершён посредством проведения новых выборов, следует обратиться к позиции партнеров Смер-СД по коалиционному соглашению. До последнего слабым звеном в нём выступала партия венгерского меньшинства Мост-Хид, которая колебалась между решением о продолжении пребывания внутри коалиции, выходе из неё или же поддержке досрочных выборов. В итоге эта партия остановилась на наиболее компромиссном решении - участие в «тройственном соглашении», но без тех лиц, которые были главными объектами общественного недовольства. Можно утверждать, что новая предвыборная кампания вряд ли смогла бы усилить её положение, поскольку, по утверждению ряда экспертов, за последние два года она стала напрямую ассоциироваться со Смер-СД. Очевидно, что досрочные выборы были на руку только оппозиционным силам, которые в ходе событий февраля-марта получили широкую поддержку среди населения, выступив как противники «политического режима Фицо». На волне всеобщего недовольства они могли получить дополнительные очки и нарушить баланс, существовавший в коалиции Смер-СД - СНC - Мост-Хид.

Впрочем, среди оппозиционных партий на данный момент не существует силы равной по своему политическому весу и влиянию Смер-СД; противники Фицо разобщены и их движение фрагментировано на различные движения и течения. Так, например, исходя из нынешних реалий, для того, чтобы сформировать правительство без присутствия социал-демократов необходимо привлечь в коалицию шесть партий ${ }^{1}$.

Что касается словаков, не вовлечённых в большую политику, которые, несомненно, стали главными действующими лицами протестного движения, то они были удовлетворены отставкой Фицо и назначением нового кабинета. Так, митинг, намеченный на 23 марта, т.е. на следующий день после назначения П. Пеллегрини, был отменён. Организаторы мероприятия отметили, что они будут отслеживать шаги нового правительства и выйдут на улицу в

\footnotetext{
${ }^{1}$ Доступ: https://www.politico.eu/article/robert-fico-slovakia-plays-the-jaroslaw-kaczynski-card/ Научно-аналитический вестник ИЕ РАН, 2018, №2
} 
случае неисполнения его обещаний ${ }^{1}$. Словацкое общество показало умеренность своих требований, нежелание привносить в политическую жизнь дестабилизирующие элементы и стремление совершенствовать политическую систему страны путём инструментов гражданского воздействия на власть.

\section{Список литературы}

Ведерников М. Словацко-российские отношения накануне председательства Словакии в Совете EC. Русский вопрос. №2, 2016. URL: http://www.russkiivopros.com/index.php?pag=one $\& \mathrm{id}=672 \& \mathrm{~kat}=6 \& \mathrm{csl}=76$.

Вишеградская четвёрка в Европейском союзе: дилеммы конвергенции. Под ред. Л.Н. Шишелиной. 2017.

Ксенофонтов А., Апашкин Д. Эволюция словацкого политического дискурса. Вишеградская Европа. Вып. 3, 2014. С. 74-90.

Марушьяк Ю. Словакия и Россия: между национальными интересами и идентичностью. Современная Европа. №7, 2017. С. 66-78.

\section{References}

Death of investigative journalist sparks mass protests in Slovakia. URL: https://www.theguardi an.com/world/2018/mar/09/death-of-investigative-journalist-sparks-mass-protests-in-slovakia.

Fico jako další Kaczyński? Svému nástupci bude dýchat na krk, píší Slováci. URL: http:// www. ceskatelevize.cz/ct24/svet/2421130-fico-jako-dalsi-kaczynski-svemu-nastupci-bude-dychat-na-krkpisi-slovaci.

Ksenofontov A., Apashkin D. Evolyuciya slovackogo politicheskogo diskursa [Evolution of Slovak political discourse]. Vishegradskaya Evropa [Visegrad Europe], 3, 2014. S. 74-90.

Marušíak J. Slovakiya i Rossiya: mezhdu nacional'nymi interesami i identichnost'yu. [Slovakia and Russia after the events in Crimea 2014 - between national interests and identity]. Sovremennaya Evropa [Contemporary Europe], №7, 2017. S. 66-78.

Organisers cancelled the Bratislava protest. URL: https://spectator.sme.sk/c/20785717/peoplewill-protest-in-streets-again-on-march-23.html.

Prezident Kiska vymenuje novú vládu, spokojný však nie je. URL: https://www.prezident.sk/ar ticle/prezident-kiska-vymenuje-novu-vladu-spokojny-vsak-nie-je.

R. Fico podal demisiu na post premiéra, nahradil ho Pellegrini. URL: http://www.teraz.sk/sloven sko/fico-podal-demisiu-na-post-predsedu-vla/314016-clanok.html.

Slovensko zažilo najväčšie demonštrácie v histórii. V Bratislave bolo podl'a odhadov 50-tisíc l'udí. URL: https://dennikn.sk/1056566/slovensko-zazilo-najvacsie-demonstracie-v-historii-v-brati slave-bolo-podla-odhadov-50-tisic-ludi/

Talianska mafia na Slovensku. Jej chápadlá siahajú aj do politiky. URL: https://www.aktuality. sk/clanok/568007/talianska-mafia-na-slovensku-jej-chapadla-siahaju-aj-do-politiky/

\footnotetext{
${ }^{1}$ URL: https://spectator.sme.sk/c/20785717/people-will-protest-in-streets-again-on-march-23.html.
} 
Vedernikov M. Slovacko-rossijskie otnosheniya nakanune predsedatel'stva Slovakii v Sovete ES [Slovak-Russian relations on the eve of Slovak presidency in Council of EU]. Russkij vopros [Russian question], 2, 2016.

Vishegradskaja chetverka v Evropejskom sojuze: dilemmy konvergencii. [Visegrad four in European Union: dilemmas of convergence]. Ed. L.N. Shishelina. Moscow, 2017.

\section{Political crisis in Slovakia 2018: R. Fico resignation and new cabinet of Pellegrini}

Author. Vedernikov M. - fellow research of Department of Central and Eastern European studies, Institute of Europe RAS, PhD in History. Address: 11-3, Mokhovaya str., Moscow, Russia, 125009. E-mail: vishma@mail.ru.

Abstract. The article shows development of the political crisis in Slovakia in February - March 2018, during which Prime Minister R. Fico was forced to resign. Subsequently new cabinet of ministers under the leadership of P. Pellegrini was appointed to power. The author focuses attention on possible consequences for Slovakia political system changes that have taken place.

Key words: Slovakia, political crisis, pre-term election, J. Kuciak, R. Fico, P. Pellegrini, Ndrangheta.

DOI: http://dx.doi.org/10.15211/vestnikieran2201812 